\title{
A cultura material no estudo das sociedades antigas
}

Ulpiano T. Bezerra de Meneses

Departamento de História - FFLCH/USP

Embora o título desta exposição $\left(^{*}\right)$ privilegie o campo da História Antiga, o problema a que se refere permeia todos os domínios da História. Certamente, no caso da Antiguidade, ele é crucial, pela raridade e fragmentação das fontes escritas. Meu propósito aqui, porém, não é montar uma apologia da cultura material, mas lançar algumas pistas para refletir sobre o alcance de um tipo de documento, as coisas físicas, como campo de fenômenos históricos, sem o qual a compreensão de uma sociedade se vê comprometida. Esta reflexão é tanto mais necessária quanto se verifica, ainda, o descaso habitual dos historiadores a respeito.

Os padrões usuais.

Na bibliografia recente de História da Grécia e de Roma, por exemplo (domínio que tomarei como referência principal), três posturas são marcantes.

(*) - Este artigo é a versão, refundida e acompanhada de notas de rodapé, do texto de conferência pronunciada no I Simpósio Nacional de História Antiga, realizado em agosto de 1983 na Universidade Federal da Paraíba, João Pessoa, e que deverá aparecer nas Atás respectivas. 
A primeira é a simples marginalização da cultura material, a supressão, no horizonte histórico, do universo físico. Autores de máxima importância, como Jean-Pierre Vernant, por vezes tanto ignoram a realidade física, que descarnam os gregos antigos, quase os transformando em zumbis, que se alimentam de puras estruturas mentais, as quais, por sua vez, dão ser à realidade social, sempre algo estática. Assim, no seu estudo do mito (aliás percuciente e, sob muitos aspectos, inovador e de muita densidade), ele utiliza apenas matéria prima literariamente processada (1); nunca levou em consideração, por exemplo, a possibilidade de matrizes visuais para as narrações míticas. Mesmo num estudo sobre, precisamente, o "nascimento das imagens" (2), o autor reduz a vastíssima problemática das "phantasiai", aparições, aparências, "eidola", imitação e outras categorias, às imagens mentais, com prejuízo para uma análise ainda mais rica.

A segunda postura talvez seja a mais freqüente de todas. E caracterizada pelo uso de aspectos da vida material, mais precisamente, da informação arqueológica, de maneira puramente instrumental. $\mathrm{O}$ papel assim desempenhado pela documentação física seria o de controle e, nos casos mais felizes, complementação da documentação textual. Daí o emprego destas fontes preponderantemente para datações ou para a confirmação ou negação daquilo que nos chegou verbalizado: é a Arqueologia do tipo "E a Bíblia tinha razão". Sirvam de exemplo os competentes comentários que A. W. Gomme, K. J. Dover e Anthony Andrewes (3) dão à obra de Tucídides: selecionam informação material apenas para iluminar o texto (objeto legítimo, é claro, de sua prioridade), mas não a sociedade - que ele documenta. Mais abrangente, S. C. Humphreys (4) faz um inventário muito rico de questões que interessam enormemente à História social e econômica da Grécia clássica e para as quais

(1) - Vernant, J. P., "Raisons du mythe", in: Mythe et société en Grèce ancienne. Paris, Maspéro, 1974: 195-250.

(2) - Vermant, J. P., "Naissance des images", in: Religions, histoires, raisons. Paris, Maspéro, 1979: 105-137. E bem verdade que, em 1983, participando de um simpósio, em Lausanne, sobre o tema sugestivamente intitulado "A cidade das imagens", Vernant reconheceu a existência de um campo "ambicioso e novo" de investigação: os sistemas figurativos, que não se constituem como simples ilustração do discurso oral ou escrito, nem como a pura reprodução figurada do real, mas se assentam no imaginário social (Institut d'archéologie et d' histoire ancienne-Lausanne/ Centre de recherches comparées sur les sociétés anciennes-Paris, La cité des images. Religion et société en Grèce antique. Paris, F. Nathan/L.E.P., 1984, prefácio: 4-5).

(3) - Gomme, A. W., K. J. Dover \& A. Andrewes, Historical commentary to Thucydides. Oxford, Clarendon Press, 1970.

(4) - Humphreys, S. C., "Archaeology and the social and economic history of classical Greece", in: Anthropology and the Greeks. Londres, Routledge and Kegan Paul, 1978: 109-130. 
os arqueológos deveriam trazer sua colaboração: sistemas de ocupação e manejo do solo, assentamentos rurais, localização espacial de lápides epigráficas, distribuição física de funções urbanas, criação e horticultura no interior das cidades, ocupação de espaços "suburbanos", reconstruções e renovaçōes de edifícios públicos e comerciais, movimentos de moedas, contextos de importação de manufaturas, estatísticas de uso, inventários de objetos domésticos, sociologia de cemitérios, morfologia e fisiologia de estruturas militares, etc. Todavia, ela também deixa de reconhecer ao mundo material sua especificidade. Para ela, como para Gomme e seus colaboradores, o emprego da informação arqueológica se esgota no "suplemento" às "evidências rarefeitas das fontes literárias". Infelizmente, até mesmo historiadores tão completos como Moses Finley (5) ou, fora da área antiga, Eric Hobsbawm (6), explicitamente atribuem tal serventia à investigação arqueológica, reforçando o status, que os antigos manuais de História the conferiam, de "disciplina ancilar da História". Finley chega mesmo a declarar que há cincunstâncias em que a documentação escrita tornaria redundante a pesquisa arqueológica, porque viria apenas corroborar informação já disponível para o historiador...

A terceira postura se pauta pelo uso "didático" das informações sobre o universo material. Estas se transformam, conseqüentemente, em ilustração daquilo que o texto já estabeleceu e, dessa forma, destinam-se a tornar mais fácil a deglutição do discurso do historiador da Antiguidade. Criam um clima que permitiria "vivenciar" situações, experiências e outras realidades que os textos nos restituem de maneira apenas verbal. A predominante maioria dos manuais e grandes séries relativas à Antiguidade segue este partido. Como exemplo, mencionem-se as coleções "Destins du monde" (Paris, A. Colin) ou "Les grandes civilisations" (Paris, Arthaud) ou certos estudos monográficos, às vezes de bom nível, mas que se apresentam sob forma de albuns fotográficos, como o trabalho de Fox sobre Alexandre Magno (7). Uma variante, de efeitos mais positivos, mas ainda assim insatisfatórios, são os estudos que tentam buscar equivalências entre produção literária e artística. Como referência, lembrem-se as obras de T. B. L. Webster sobre a Grécia arcaica e clássica e, em especial, seu estudo das convergências da poesia e da arte helenística (8).

(5) - Finley, M. I., - "Arqueología e História". in: Uso y abuso de la Historia, trad. esp., Barcelona, Grijalbo, 1977: 131-156.

(6) - Hobsbawm, E. J., - "An Historian's comments", in: Burnham, B. C. \& J. Kingsbury, orgs., Space, hierarchy and society. Londres, BAR International Series, 59, 1979: 247-253.

(7) - Fox, R. L., The search for Alexander. Londres, Allen Lane, 1980.

(8) - Webster, T. B. L., Hellenistic poetry and art. Londres, Methuen, 1964. 


\section{O suposto viés da documentação material.}

Essas três posturas partem de algumas poucas alegações equivocadas sobre a natureza da documentação material ou sobre a dificuldade de seu emprego.

Uma de tais alegações é que as coisas materiais constituiriam uma parcela apenas - e bem reduzida - dos fenômenos históricos. Em outras palavras, haveria fenômenos fundamentais do universo social (formas de organização social e política, domínio mental e assim por diante), que não se expressam materialmente, de maneira imediata, nem têm sempre contrapartida na realidade material. Seria pois o universo material um segmento inexpressivo, incluindo apenas aqueles aspectos da vida social e cultural capazes de se consubstanciarem em coisas físicas, corpóreas. Os objetos não são idéias, diz-se, embora possam "expressá-las" ou "refleti-las".

Outra objeção é que, além de parcial, a documentação material seria aleatória, pois chega até nós após triagens sucessivas e sem controle. Assim, o chamado "depósito arqueológico" (representado principalmente pelo sítio arqueológico) seria o produto de inúmeros filtros culturais e naturais. Culturais, na medida em que o sítio arqueológico é composto principalmente de restos das coisas materiais: o que sobrou como resultado de certos padrões de rejeito, abondono, perda causal... Naturais, na medida em que, sobre essa deposição, há ainda a interferência de fatores biológicos, clima, ação de animais e outros organismos, processos geomorfológicos, etc., que condicionam seu estado de conservação e, mesmo, sua sobrevida. Os especialistas acreditam que, por exemplo, do material orgânico, mesmo em condições satisfatórias de conservação, não se tem mais que um resíduo de $10 \%$ do original (9).

Finalmente, costuma-se dizer, também, que existiria um fosso intransponível ou, pelo menos, considerável, entre sítio o arqueológico e o sistema cultural, que o produziu (10). Nessa ótica, o sítio arqueológíco - expressão espacial do depósito arqueológico - deveria ser entendido segundo um duplo registro, não coincidente. De um lado, tem-se a realidade empírica: aquele pedaço de chão que é uma unidade espacial

(9) - V. Rathje, William L. \& Michael McCarthy, "Regularity and variability in contemporaneous garbage", in: South, Starley, org., Research strategies in historical archeology. New York, Academic Press, 1977: 275; v. também, para condições gerais de conservação, Gifford, Diane P., "Ethnoarchaeological observations of natural processes affecting cultural materials", in: Gould, Richard A., org., Explorations in Ethnoarchaeology, Albuquerque, University of New Mexico Press, 1979: $77-101$.

(10) - Schiffer, M. B., - "Archaeological context and systemic context", American Antiquity, 37- 1972: 156-165. 
de concentração de restos culturais, espécie de arquivo, mas referente, sobretudo, a outros espaços. Em contrapartida, tem-se o sítio como entidade sociológica, isto é, campo de atividades e relações. Ora, entre os dois não há, normalmente, correspondência, salvo exceções dignas de nota (entre as quais as áreas funerárias). Via de regra, portanto, o que caracteriza um depósito arqueológico, aquilo que constitui a essência de um sítio arqueológico, é o lixo, isto é a presença do que foi excluído do ciclo vivo da atividade cultural. Esta exclusão é que transforma objetos em documentos: o objeto de seus produtores e usuários originais passa a valer, aos olhos de um "observador", apenas enquanto suporte físico de informação. O documento se institui, assim, por referência a um terceiro, a um sujeito externo. A situação-limite, que importa num esvaziamento total do valor de uso, contrabalançado por uma ascensão do valor de troca (vide o caso do objeto "histórico", "antiguidade") se perfaz e institucionaliza na coleção, no museu.

Todas estas alegações contêm muito de enganoso, ambíguo, sofismático, mesmo. Assim, por exemplo, ressaltar o caráter "parcial" dos fenômenos materiais é estabelecer uma distinção, carecedora de fundamentos, entre os componentes materiais e não materiais da cultura, dando a estes últimos uma autonomia que eles não podem ter. Esta dicotomia desfigura o próprio conceito de cultura, em que estão embutidas e indissociáveis a prática e a representação: a intervenção do homem sobre o real e a representação desse real e da ação humana, como integrantes do real, diferentes apenas nas funções (11). Ora, cindir radicalmente cultura material e cultura não material é ignorar a ubiquiidade das coisas materiais, que penetram todos os poros da ação humana e todas as suas circunstâncias. Por outro lado, é preciso não confundir a natureza física do suporte de informação com a natureza física de um fenômeno. Nenhum historiador ou cientista social se depara, na primeira esquina, com uma instituição política, um sistema sócio-cultural, um modo de produção, uma formação histórica... Também nos textos, como na documentação material, se procede por inferência e abstração. Finalmente, não se pode desconhecer que os artefatos - parcela relevante da cultura material - se fornecem informação quanto à sua própria materialidade (matéria prima e seu processamento, tecnologia, morfologia e funções, etc), fornecem também, em grau sempre considerável, informação de natureza

(11) - Discutindo problema paralelo, Maurice Godelier previne contra a total inadequação de distinguir infra-estrutura e superestrutura enquanto níveis ou instâncias diferentes e não enquanto funções. As representações mentais são parte integral das relações sociais, desde que estas começam a se definir e constituem uma das condiçōes de sua definição (Godelier, M., "The ideal in the real", in: Samuel, Raphael \& Gareth S. Jones, orgs., Culture, ideology and politics. Londres, Routlegde and Kegan Paul, 1982: 12-38). 
relacional. Isto é, além dos demais níveis, sua carga de significação refere-se sempre, em última instância, às formas de organização da sociedade que os produziu e consumiu.

Nesse campo, tem havido avanço muito grande das disciplinas interessadas nos objetos. Assim, por exemplo, a semiologia de um Abraham Moles (12) ou de Jean Baudrillard (13) ressaltam que o verdadeiro estatuto do objeto não deriva de uma teoria das necessidades e sua satisfação, mas das prestações sociais e sua significação. Nesta esteira, chega-se até à sociologia do consumo, em que uma Mary Douglas, por exemplo, supera com enfoque antropológico uma análise estritamente econômica, definindo seu problema não como a apropriação de bens materiais, mas a constituição e operação de um sistema de comunicação (14). Semelhantemente, o estudo do vestuário, por Marshal Sahlins (15) (que, todavia, às vezes corre o risco de sucumbir a um mentalismo abstrato), rompendo as barreiras da análise morfológica, tecnológica e funcional, desemboca em sistemas cognitivos e operações classificatórias. Dentro dessa perspectiva, consumir é classificar e estabelecer vias de comunicação: os diversos níveis de resposta às necessidades atendidas pelo vestuário (proteção do corpo contra frio e calor, pudor, etc.) não esgotam sua significação, que terá que ser procurada na emissão de mensagens identificadoras de sexo, idade, profissão, grupos diversos, status e muito mais, localizando o usuário e seus interlocutores numa constelação de relações dentro da sociedade - para que efetivamente se organizem tais relações. Cumpre lembrar que não basta dispor de uma organização cognitiva do universo, de uma taxonomia precisa e adequada, de um código, para ordenar a realidade; é preciso que esse código seja eficiente e, para tanto, são indispensáveis sinais físicos que estabeleçam, nas diversas situações concretas, a leitura do jogo de direitos e obrigações, valores, expectativas, e assim por diante. Nas sociedades simples, é absolutamente vital este balizamento propiciado pela "visibilidade" de certas coisas materiais (daí as formas "estéticas" $=$ que aguçam a percepção e, assim, o contacto entre o sujeito e o mundo exterior).

$\mathrm{O}$ argumento de que a cultura material chega até nós desfigurada por sucessivas e diversificadas triagens igualmente se mantém com difi-

(12) - Moles, A., Théorie des objets. Paris, Eds. Universitaires, 1972.

(13) - Baudrillard, J., Pour une critique de l'économie politique du signe. Paris, Gallimard, 1972; Le système des objets. La consommation des signes. Paris, Denöel/Gonthier, 1968.

(14) - Douglas, Mary, "Goods as a system of communication", in: In the active voice. Londres, Routledge and Kegal Paul, 1982: 16-43; Douglas, $M$. \& Baron Isherwood, The world of goods. Toward an Anthropology of consumption. Harmondsworth, Penguin, 1980. 1979 .

(15) - Sahlins, Marshal, Cultura e razão prática, trad. bras. Rio, Zahar, 
culdade. Também os textos passam por triagens comparáveis e às vezes mesmo mais radicais (16). Tome-se como referência o caso da Grécia antiga, aparentemente tão rica em documentação textual: basta lembrar que, se dela tirarmos o material epigráfico, sobra-nos pouco mais que antologias selecionadas pelos eruditos alexandrinos, que, a partir do século IV a. C., coletaram e recopilaram textos antigos, naturalmente segundo seus critérios de valor e interesses, historicamente definíveis. Além disso, esta triagem se desdobra em circunstâncias, às vezes fortuitas, das condições de conservação. A própria Biblioteca de Alexandria, que se acredita ter possuído cerca de 700.000 volumes (17), atingida por incêndio, legou-nos ínfima parcela desse acervo. Doutra parte, é questão absolutamente irrelevante saber se se dispõe da "totalidade" da documentação, de meia totalidade, ou apenas $5 \%$ dela. O conhecimento científico não cuida de universos íntegros (noção, aliás, que seria oneroso definir), mas trabalha por amostragem e abstração. O que importa, então, é se temos elementos suficientes para compor, instaurar, definir um sistema documental, que é produzido pela operação de conhecimento do historiador. Ele não existe em estado "natural": as coisas físicas não são documentos, são, isto sim, fenômenos da natureza e é a operação do historiador que cria o campo documental (o mesmo poderia ser dito dos textos, não obstante a existência de certas categorias específicas de documentos "de nascença"). Indispensável, pois, é dispor de material para integrar um campo inteligível e um sistema orgânico, passível de leitura. E preciso reconhecer, contudo, que uma parte das críticas feitas por aqueles que marginalizam a cultura material tem razão quanto a certos vícios dos arqueólogos, sobretudo na medida em que as coisas materiais são por eles frequientemente tratadas como se fossem realidades em si, à parte, reificadas.

Retomando o argumento da filtragem do documento material, seria oportuno recordar que a Arqueologia desenvolveu uma série de possibilidades no controle, por exemplo, dos processos geomorfológicos na formação e perturbação do depósito arqueológico e assim também de sua gênese cultural (18). A chamada Etno-arqueologia (19), que procura

(16) - V. Gabba, Emilio, "Literature", cap. 1 de Grawford, Michael, org., Sounces for ancient History. Cambridge, University Press, 1983: 1-79.

(17) - V. Cavallo, G., Libri, editori e pubblico nel mondo antico. Bari, Laterza, 1977.

(18) - Wood, Raymond W. \& Donald Lee Johnson, "A survey of disturbance processes in archaeological site formation", in: Schiffer, M. B., org., Advances in archaeological method and theory, 1. New York, Academic Press, 1978: 315-384.

(19) - V. Ingersoll, D., J. E. Yellen \& W. Macdonald, orgs., Experimentat Archaeology. New York, Columbia University Press, 1977; Kramer, Carol, org., Ethnoarchaeology. Implications of Ethnography for Archaeology. New York, Columbia University Press, 1979; Gould, Richard A., org., Explorations in Ethno- 
observar, em sociedades contemporâneas, situações que esclareçam problemas arqueológicos, elegeu o problema do lixo como uma de suas prioridades, buscando entender os padrões de rejeito, formação, organização espacial, duração e vida útil de artefatos, correlações com outros aspectos relevantes da organização sócio-econômica e questões semelhantes. Ora, no caso do texto, exceção feita ao trabalho puramente filológico, não creio que haja controles adequados. Aquilo que muitos especialistas chamam de "o trabalho do texto", levando em conta as condições de constituição do documento, os horizontes de expectativa, a gama de leituras, etc. - e a consideração da linguagem verbal como fato social, ela própria, assim como a escrita - nada disso é, ao que parece, preocupação corrente ou marcada, entre os historiadores da Antiguidade.

Por fim, o argumento de que há solução de continuidade, com conseqüências irreparáveis, entre objeto e documento, também merece ser reposto. Antes de mais nada, fique claro referir-se tal viés também ao documento textual, embora se manifeste mais agudamente em nosso caso. É possível, porém - e necessária - a operação de "desdocumentalização", que recupera as diversas trajetórias do artefato. $\mathrm{Na}$ situação típica, parte-se do estágio final, o rejeito (que pode comportar reparações, re-uso, reciclagem), para o inicial, da aquisição da matéria prima, passando-se pelo consumo, circulação, produção. Esta perspectiva requer que se dê à produção e ao consumo igual peso ao que é dado ao produto. Dessa forma, consegue-se desfetichizar o artefato. Por esse ângulo, o problema da classificação dos artefatos não pode mais pressupor categorias universais, estáticas, de tipo naturalista, transposição, para a vida sócio-cultural, do que Lineu propôs para os organismos vivos. É preciso, ao contrário, entender a classificação como um recurso heurístico, destinado a evidenciar os pontos marcantes das diversas trajetórias do artefato. A esse respeito, aponte-se a importância que poderão ter as categorias cognitivas (20).

$O$ viés da documentação textual.

Invertendo a posição até agora assumida, é possível apontar, no uso da documentação textual, dificuldades a que escapa a documentação material.

archaeology. Albuquerque, University of New Mexico Press, 1979; Tooker, Elisabeth, org., Ethnography by archaeologists. Washington, American Ethnological Society, 1982 .

(20) - V. Kempton, Willet, The folk classification of ceramics. A study of cognitive prototypes. New York, Academic Press, 1981. 
A primeira destas dificuldades é a coincidência, tão freqüentemente pressuposta, entre fato real e fato de conhecimento, na manipulação da informação verbal. Claude Lefort (21) apontou com pertinência a falsidade desta coincidência, que colocaria como meta ideal para o historiador a "restituição": o acontecimento encontraria seu modelo na observação exata, observação que se legitimaria na convicção segundo a qual aquilo que foi possuía em si sua própria identidade. Assim, apreendido como alguma coisa dada a saber, 0 acontecimento pediria apenas para ser identificado. Ora, reafirma Lefort (22), o acontecimento é instaurado pela operação de conhecimento (como já vimos), de maneira que é uma ilusão dispor, de um lado, os fatos, de outro, a teoria. No caso da documentação arquivística, esta ilusão se desdobra e agrava na medida em que se estabelece coincidência entre fato real e relato verbal (eu diria, quase, fato verbal). No entanto, o documento escrito é essencialmente representação (e, enquanto tal, naturalmente, parte da realidade a que se refere). Não é o equivalente verbal. Sally Humphreys (23) observa, com justeza, que as fontes textuais antigas são mais aptas a informar sobre representações (valores, em particular), do que sobre as bases estruturais que as sustentam. Naturalmente, o documento material também pode ter carga representantiva (figura, imagem, iconografia), mas é menor o risco de confundi-lo com o nível verbal. Vale lembrar o esforço de Pierre Francastel, procurando situar as formas visuais entre as diversas classes de pensamento. O pensamento cartesiano não é o único modo de pensamento racional, o pensamento racional não é o único modo de pensamento: existe um pensamento plástico, como existe um pensamento matemático. $O$ pensamento plástico, aquele que se organiza segundo formas visuais e cria o que Francastel denomina campo figurativo (ou realidade figurativa) (24), não é uma transposição gráfica, pictórica, escultórica, de uma realidade verbal, mas é um domínio próprio. "Diga-o com flores" é uma sugestão enganosa, nesta área, em que as palavras e as coisas devem guardar sua especificidade. A natureza mesma da documentação material previne o investigador do risco de considerá-la reflexo, correspondência, em nível físico, de fenômenos de outra matriz.

(21) - Lefort, Claude, As formas da História, trad. bras. São Paulo, Brasiliense, 1979: 257-259.

(22) - Ib.: 257.

(23) - Humphreys, S. C., "The social structure of the ancient city", in: Anthropology and the Greeks. Londres, Routledge and Kegal Paul, 1978: 201.

(24) - Francastel, P., La réalité figurative. Paris: Gallimard, 1968. 


\section{O potencial da documentação física. A cultura material.}

Ao contrário, várias vantagens fornecidas pelo documento material podem ser listadas (25). Já se mencionou sua ubiqüidade, que não encontra paralelo na documentação textual. Acrescente-se sua menor permeabilidade ideológica, as facilidades para tratamento quantitativo e comparativista, o caráter preponderante de anonimato. Tal caráter de anonimato, associado à serialidade, à repetição, faz dos artefatos excepcional veículo para estudo de um domínio para cuja importância visceral os historiadores, nos últimos anos, têm chamado a atenção: o quotidiano, o domínio do banal, da purificação do evento, das tendências quase em estado "natural". Quanto a estes aspectos, a documentação escrita raramente oferece equivalência: 0 banal e a recorrência não costumam integrar as prioridades do registro escrito. Analisando as ramificações recentes da "Escola dos Annales", Jacques Le Goff (26) notava que a História (na França), depois de se ter tornado sociológica, está-se transformando em "etnográfica" (diríamos antropológica), tendo como um dos eixos fortes a definição e entendimento do universo quotidiano, impossível de recuperar e analisar sem a intervenção das coisas materiais.

O que foi dito até aqui já permite precisar e alargar o conceito mesmo de cultura material.

Por cultura material poderíamos entender aquele segmento do meio físico que é socialmente apropriado pelo homem. Por apropriação social convém pressupor que o homem intervém, modela, dá forma a elementos do meio físico, segundo propósitos e normas culturais. Essa ação, portanto, não é aleatória, casual, individual, mas se alinha conforme padrões, entre os quais se incluem os objetivos e projetos. Assim, o conceito pode tanto abranger artefatos, estruturas, modificações da paisagem, como coisas animadas (uma sebe, um animal doméstico), e, também, o próprio corpo, na medida em que ele é passível desse tipo de manipulação (deformações, mutilações, sinalações) ou, ainda, os seus arranjos espaciais (um desfile militar, uma cerimônia litúrgica).

Para analisar, portanto, a cultura material, é preciso situá-la como suporte material, físico, imediatamente concreto, da produção e reprodução da vida social. Conforme esse enquadramento, os artefatos - que

(25) - Para alguns aspectos, v. Snodgrass, Anthony, "Archaeology", cap. 3 de Crawford, M., org., Sources for ancient History. Cambridge, University Press, 1983: 137-184.

(26) - Le Goff, Jacques, "L'historien et l'homme quotidien", in: Mélanges Braudel, Toulouse, vol. 2, 1973: 235-243. 
constituem, como já foi afirmado, o principal contingente da cultura material - têm que ser considerados sob duplo aspecto: como produtos e como vetores de relações sociais. De um lado, eles são o resultado de certas formas específicas e historicamente determináveis de organização dos homens em sociedade (e este nível de realidade está em grande parte presente, como informação, na própria materialidade do artefato). De outro lado, eles canalizam e dão condições a que se produzam e efetivem, em certas direções, as relações sociais. Em conseqüência, a Arqueologia não precisa mais ser definida como a disciplina que se ocupa dos artefatos, das coisas materiais e seu contexto (isto 6 , das manufaturas e das relações espaciais nas quais elas se apresentam), mas poderia ser recebida no convívio das demais ciências sociais. Em outras palavras, também a Arqueologia estuda os sistemas sócio-culturais, sua estrutura, seu funcionamento e seu comportamento ao longo do tempo, sua mudança (27). A particularidade está em que, para essas operações, ela conta exclusiva ou preponderantemente com informação derivada dos restos materiais - a cultura material. Não hesito, pois, em considerar a Arqueologia como História da cultura material.

\section{Experimentação e perspectivas.}

Estas propostas teóricas me parecem sólidas e são atraentes. Devese reconhecer, todavia, que os frutos que elas geraram são ainda parcos. Nem poderia ser de outra forma, já que ainda está para ser elaborada uma verdadeira teoria da cultura material, sólida e abrangente. Não obstante, vale a pena examinar o esforço que vêm desenvolvendo muitos arqueólogos, para trabalharem como cientistas sociais. Trata-se, apenas, de uma seleção assistemática de exemplos, que pode marcar algumas orientaçōes e, mais que tudo, confirmar a fertilidade dessa linha.

Uma das pistas para o estudo da organização social está nas tentativas de inferir características dos grupos domésticos, regras de residência, etc., a partir de alguns aspectos sensíveis da cultura material, como é, por exemplo, o chamado micro-estilo. James Deetz e William Longacre (28), interpretando a evolução da cerâmica proto-histórica Arikara (SW americano) - cuja fabricação, de natureza familiar, deve ser atribuída às mulheres - percebem que o enfraquecimento das associações de atributos decorativos podia ser explicado por mudança da

(27) - V. Bezerra de Meneses, U., "La 'New Archaeology': 1'Archeologia comme scienza sociale", Dialoght di Archeologia, III S., 1, 1983: 11-19.

(28) - Deetz, James, The dynamics of stylistic change in Arikara ceramics. Urbana: University of Illinois, 1965; Longacre, William, Archaeology as Anthropology. A case study. Tucson, The University of Arizona Press, 1970. 
matrilocalidade e restrição da circulação das mulheres como parceiras conjugais, entre as aldeias: quanto maior a circulação (exogamia), anteriormente, tanto mais sensível a homogeneidade e estabilidade dos micro-estilos. Michael Spence (29), analisando traços não métricos de material osteológico, pode detectar em Teotihuacán, no México (núcleo urbano caracterizado, no seu período clássico, por grandes unidades habitacionais isoladas), não só residência virilocal, como o desenvolvimento de bairros artesanais especializados no trabalho da obsidiana e sua vinculação a grupos masculinos aparentados. Já James Rock (30), envolvido com a formulação de modelos explicativos da organização dos Pueblo pré-históricos, examina as estruturas de habitação em sua dinâmica (ampliações, refacções, reciclagens, etc.), para definir os grupos domésticos e seu "ciclo de desenvolvimento".

Em outro quadrante, James Hill e Joel Dunn (31) têm procurado recuperar o nível do indivíduo nos estudos de cultura material. Não é o caso, evidentemente, de ressaltar singularidades, muito menos de qualquer perspectiva páleo-psicológica. Antes, desenvolvendo propostas há muito formuladas por Marcel Mauss, por exemplo (que incluíam na cultura o corpo, a postura, os hábitos corporais), trata-se de analisar o artefato nas suas relações com o corpo, como nos padrões de uso, detectáveis pelas marcas de desgaste. Particularmente frutuoso é considerar o artefato também como produto de certos padrões corporais, ações caracterizáveis por formas de mobilizações do corpo, em que sempre há um conteúdo pessoal forte. Isto permite, num conjunto de artefatos, isolar atribuições a indivíduos e, daí, apreender vários aspectos relevantes da organização técnica e social do trabalho: decomposição da produção em unidades distintas de operação, hierarquias, níveis diferenciais de qualificação técnica, estatística da especialização num grupo, mecanismos de inovação ou reforço da tradição, graus de flexibilidade no uso pessoal do repertório artesanal do grupo, socialização das invenções e assim por diante.

Outro tipo de estudo que tem merecido particular atenção é o que diz respeito às análises espaciais. Com efeito, o espaço é um suporte fundamental para entender atividades, relações, organização. Dessa forma, cumpre apontar, num leque variadíssimo de possibilidades, desde aqueles trabalhos que se preocupam com a proxemística (análise do conteúdo

(29) - Spence, Michael W., "Residential practices and the distribution of skeletal traits in Teotihuacan, Mexico", Man, 9 (2), 1974: 262-274.

(30) - Rock, James T., "Prehistoric Pueblo organization", The Kiva, 35, 1969: 15-24.

(31) - Hill, James N. \& Joel Gunn, orgs., The individual in Prehistory. Studies of variability in style in prehistoric technologies. New York, Academic Press, 1977. 
espacial da atividade humana, e em particular do comportamento cultural), até os de território e territorialidade, passando pelos estudos locacionais, de dispersão e concentração de assentamentos e formação de pontos, nódulos, redes, hierarquias dos sistemas de assentamento, ou, então, a micro-análise de áreas de atividade (32). O espaço, nestes casos, nunca é tratado como cenário da ação cultural, mas como ingrediente seu, físico. A chamada Arqueologia Industrial também tem dado realce a esta questão, pela significações novas e diagnósticas que o espaço assume, após a Revolução Industrial, e que pode levar a questões interessantes. Um excelente exemplo é o de B. Forestier (33), que efetua sua investigação sobre os arsenais da marinha francesa dos séculos XVIII e XIX, observando a crise do saber secreto das corporaçōes de ofício e a necessidade de difusão do saber novo, proposto por uma racionalidade abstrata e universal, e exigido por uma fundamentação "técnica", a que respondem técnicos especializados. Ora, o primeiro nível concreto sobre o qual se manifesta essa nova forma de saber é precisamente a organização do espaço. No caso dos arsenais, não há mais um chão em que se assentem as estruturas, mas é o espaço que ordena as atividades, seu fluxo, a comunicação, a hierarquização, em função das exigências racionais da produção e da organização do trabalho: unidades (produção, administração, depósito) compartimentadas, níveis topográficos diferentes (inclusive artificiais), caminhos sob controle, etc. E por isso que ele pode dizer que esse é o primeiro espaço emblemático da Revolução Industrial.

Como exemplo também das tentativas de estudar aspectos da organização social a partir da análise da cultura material, vale a pena mencionar as pesquisas demográficas. Sua importância fica explícita quando se considera que, sem a demografia, não há escala dos fenômenos sociais. Não se trata, pois, de simplesmente equacionar problemas (principalmente por intermédio da análise de restos ósseos) referentes a densidade e composição da população, distribuição por sexo, idade, índices de mortalidade, taxas de reposição, estatísticas vitais, enfim, mas o objetivo é entender formas de organização social. Assim, os restos alimentares podem ser convertidos, como aconteceu com sambaquis (concheiros) da Califórnia,

(32) - Para uma amostra dos enfoques, v. Hodder, I., The spatial organisation of culture. Londres, Duckworth, 19787; Hodder, I. \& C. Orton, orgs., Spatial analysis in Archaeology. Cambridge, University Press, 1976; Clarke, D. L', org., Spatial Archaeology. New York: Academic Press, 1977; Findlow, F. J. \& J. E. Ericson, orgs., Catchment analysis. Essays on prehistoric resource space. Los Angeles, Anthropology UCLA, 1980; Paynter, R. Models of spatial inequality. Settlement patterns in Historical Archaeology. New York, Academic Press, 1982: 21-44.

(33) - Forestier, B., apud Carandini, A., "Archeologia industriale", Ricerche di Storia dell'arte, 7, 1978: 5-9. 
nas investigações de Maxwell, Gilbard, Treganza e outros (34), em calorias - o que permite quantificar população e, pela distribuição espacial, desvendar aspectos da alocação diferenciada de recursos. Também os artefatos foram usados para informação demográfica. $\mathrm{Na} \mathrm{In}$ glaterra do século XI, por exemplo, J Russel (35) viu, como artefatoíndice, $o$ arado de ferro, com bons resultados. Inúmeros pesquisadores fizeram o mesmo com mós de pedra, na Meso-américa e sudoeste dos Estados Unidos (36). Também mudanças populacionais foram diagnosticadas por Turner e Logfren (37) no estudo da variação de duas séries contemporâneas de culturas proto-históricas americanas: uma constituída por tigelas (cuja função, pela morfologia e outros caracteres, seria a distribuição do alimento em porções individuais) e que se manteve estável na capacidade, ao longo do tempo examinado; a outra, constituída por vasos que iam ao fogo (associados, portanto, a funções de processamento do alimento) e que quase duplicaram sua capacidade original. Foi possível, daí, inferir aumento de população e, ao mesmo tempo, seus parâmetros, por unidade familiar, na quantificação do material total. Outro problema atentamente considerado é o das correlações entre área ocupada ou área de ahbitação e população. Embora haja ainda muita divergência, os trabalhos de Naroll, Cook, Heizer, Treganza e outros, já abriram pistas importantes (38).

Para finalizar, recorde-se o campo mais antigo de estudos desta natureza: os contextos funerários, terreno propício para entender status, hierarquias, diferenciação social e econômica e questões semelhantes. Deve-se observar, porém, que os problemas são hoje vistos como muito mais complexos e que os contextos funerários são examinados como parte de configurações sociais totais (39).

(34) - Apud Cook, Sherburne F., Prehistoric Demography. Reading, Addison-Westely Modular Publications, 16, 1972; v. também Hassan, Fekri, "Demographic Archaeology", in: Schiffer, M. B., org., Advances in archaeological method and theory, 1, New York, Academic Press, 1978: 49-105.

(35) - Russell, J. C., "Late ancient and mediaeval population", American Philosophical Society, Transactions, N. S., 48, 1958: 1-52.

(36) - Cook, S. F., op. cit.: 11.

(37) - Turner, C. G., II \& Laurel Lofgren, "Household size of prehistoric Western Pueblo indians", Southwestern Journal of Anthropology, 22, 1966: 117-132.

(38) - V. Casselberry, S. E., "Further refinement of formulae for determining population from floor area", World Archaeology, 5 (1), 1974: 117-123.

(39) - V. Humphreys, S. C. \& Helen King, orgs., Mortality and immortality: the anthropology and archaeology of death. New York, Academic Press, 1981; Chapman, Robert, Ian Kinnes \& Klavs Randsborg, orgs., The archaeology of death. Cambridge, University Press, 1981; Pader, Ellen-Jane, Symbolism, social relations and the interpretation of mortuary remains. Londres, BAR Intertional Series, 130, 1982; Gnoli, Gherardo \& Jean-Pierre Vernant, orgs., La mort, les morts dans les sociétés anciennes. Cambridge, University Press/Paris: Maison des Sciences de l'Homme, 1982. 
Os exemplos expostos não dão um panorama sistemático e abrangente das questões - nem mesmo dizem respeito à História da Antiguidade, sobretudo porque neste campo a contribuição teórica e metodológica te msido praticamente inexistente. Todavia, deixam claro o potencial da cultura material na exploração de informação que ultrapassa o domínio usual da cronologia, tecnologia e organização econômica (subsistência). Deixam claro, igualmente, que a cultura material constitui um código próprio, a ser descriptado segundo sua natureza e não por redução aos códigos verbais. Demonstram, finalmente, que na integração dos aspectos materiais e não materiais da cultura e na correlação dos padrões de organização material e de comportamento ainda há muito caminho a ser percorrido. Muitas perguntas nunca serão respondidas. Fica óbvio, porém, que outras muitas não foram até hoje respondidas porque nunca foram propostas. 